\title{
La tenencia de mascotas en edificios de propiedad horizontal y su prohibición por reglamento de copropiedad
}

Pets in buildings of horizontal property and their prohibition by coownership regulation

\section{Agustín Fascioli Mochetti ${ }^{1}$}

'Universidad Católica del Uruguay. afasciolimochetti@gmail.com https://doi.org/10.22235/rd.v0i17.1575

ReSUMEN: El objeto del presente texto es analizar la legalidad de las cláusulas de reglamentos de copropiedad que prohíben la tenencia de animales domésticos. El estudio se realiza a la luz de lo dispuesto por los distintos instrumentos jurídicos que reconocen y consagran el derecho de propiedad, así como de la Ley 18.471 y su Decreto Reglamentario 204/017, referentes a la protección, bienestar y tenencia responsable de animales. Se estudiarán las diversas situaciones que pueden ser objeto de diferendos en los edificios de propiedad horizontal, y se analizará el derecho aplicable al caso concreto. Palabras ClaVe: propiedad horizontal, mascotas, derecho de propiedad, reglamento de copropiedad. 
ABStACT: The purpose of this text is to analyse the legality of the clauses of the Coownership regulations prohibiting the holding of domestic animals. The study is carried out in the light of the provisions of the different legal instruments that recognise and consecrate the right of property, as well as of the law 18,471 and its Regulatory decree 204/017, concerning the protection, welfare and responsible holding of animals. The various situations that may be the subject of disputes in the buildings of horizontal ownership will be studied, and the law applicable to the specific case will be analyzed.

KEY-WORDS: horizontal property, pets, property right, coproperty regulations.

SUmario: I. Introducción. II. Animales de compañía; a) Definición de mascota; su condición frente al Derecho; b) Protección de las mascotas; normas de responsabilidad social. III. El derecho de propiedad. a) Concepto y límites; b) Limitación al derecho de propiedad por disposiciones del reglamento de copropiedad; c) Tenencia irresponsable de animales que causen perjuicios a copropietarios. IV. Conclusiones. Bibliografía. 


\section{INTRODUCCIÓN}

Las múltiples consultas que administradores de edificios y copropietarios realizan sobre el tema, así como la inexistencia de legislación específica, han hecho ver la conveniencia de un texto breve que aporte respuesta. Se trata entonces de analizar la legalidad de las cláusulas de los reglamentos de copropiedad que prohíben la tenencia de mascotas o animales de compañía en los edificios de propiedad horizontal, a la luz de la regulación legal del derecho de propiedad y las disposiciones de la Ley 18.471 de protección animal y su decreto reglamentario.

La hipótesis de trabajo es que la prohibición de mascotas o animales de compañía se debe a la inexistencia de normativa específica que lo regule.

Para responder a la pregunta sobre la licitud de estas prohibiciones, se analizará la normativa vigente en la materia, teniendo en cuenta las posiciones doctrinarias y la existencia de antecedentes jurisprudenciales. Se consultará a los autores más reconocidos sobre los tópicos analizados, y la eventual existencia de disputas judiciales por prohibición de tenencia de mascotas. 


\section{ANIMALES DE COMPAÑíA}

\section{A) DEFINICIÓN DE MASCOTA; SU CONDICIÓN FRENTE AL DERECHO}

El artículo 8 de la Ley $18.471^{1}$ define a los animales de compañía como aquellos que sean mantenidos sin intención lucrativa y que por sus características y su comportamiento puedan convivir normalmente con el hombre, en un ambiente doméstico, recibiendo la debida atención, protección, alimentos y cuidados, ejerciendo de esta forma una tenencia responsable. Ante esto, es importante determinar qué se entiende por ejercicio de tenencia responsable, y al respecto la ley ha señalado que se desarrolla en aquellas situaciones en las cuales el tenedor del animal lo mantenga en condiciones físicas y sanitarias adecuadas, le proporcione alimentos, alojamiento y abrigo cuando sea necesario, y cumpla con las normas reguladoras del paseo y manejo de los animales. Asimismo, es necesario que el tenedor del animal cumpla con las normas de responsabilidad social vigentes.

Conforme a lo dispuesto por el Decreto 204/017², los animales no son sujetos de derecho, sino que se considera que son bienes de propiedad privada ${ }^{3}$, pero por su carácter de seres vivos se someten a un régimen jurídico especial, determinado por la ley de protección animal y su decreto reglamentario.

En efecto, deben gozar de ciertos bienes o libertades reconocidos también por la Organización Mundial de Sanidad Animal ${ }^{4}$, y, conforme a nuestro derecho, todo tenedor de animales deberá respetar:

1. Libre de hambre, sed y desnutrición: el tenedor del animal deberá asegurarle a su mascota un acceso fácil y permanente a agua fresca y alimentos.

2. Libre de incomodidades físicas o térmicas: el animal deberá estar rodeado de un ambiente adecuado, en el cual tenga una confortable área de reposo.

Ley 18.471 de fecha 21 de abril de 2009. Artículo 8: "Será considerado como animal de compañía todo aquel animal que sea mantenido sin intención lucrativa y que por sus características evolutivas y de comportamiento pueda convivir con el ser humano en un ambiente doméstico, recibiendo de su tenedor atención, protección, alimento y cuidados sanitarios.”

2 Decreto Reglamentario de la Ley 18.471. Artículo 11: "No siendo los animales sujetos de derecho, los mismos serán considerados como bienes de propiedad privada sujetos a una normativa especial..."

3 Ana Rita Colombo, integrante de la Comisión de Bienestar Animal señala que la COTRyBA (Comisión de Tenencia Responsable y Bienestar Animal) se basa en un informe del departamento jurídico del Ministerio de Educación y Cultura para afirmar que los animales son objetos de propiedad. https://www.elpais.com.uy/informacion/polemicatenencia-mascotas-edificios.html consultado el día 15 de febrero de 2018.

4 http://www.oie.int/es/bienestar-animal/el-bienestar-animal-de-un-vistazo/. Acceso el día 09 de febrero de 2018. 
3. Libre de dolor, lesiones y enfermedades: se deberá realizar la prevención y el tratamiento adecuado de patologías.

4. Libre de expresar su conducta normal: se le otorgará espacio suficiente para poder expresar las pautas propias de su comportamiento.

5. Libre de miedo y angustia: se asegurará un entorno afectivo y no agresivo.

\section{B) PROTECCIÓN DE LAS MASCOTAS; NORMAS DE RESPONSABILIDAD SOCIAL}

El derecho positivo vigente en materia de protección y tenencia de animales dispone que aquellos tenedores de animales de compañía deberán cumplir necesariamente con normas de responsabilidad social, de entre las cuales se destacan las siguientes ${ }^{5}$ :

1. Inscribirlo en el Registro Nacional de Animales de Compañía,

2. Impedir que el comportamiento del animal pueda molestar o causar daño a las personas, a los bienes de terceros o a otros animales, asumiendo total responsabilidad en caso de que suceda.

3. Velar por que la presencia del animal no signifique un perjuicio o deterioro del medio ambiente.

4. Mantener al animal sujeto con correa cuando circule en la vía pública, y no dejarlo suelto en lugares de libre acceso al público.

5. Impedir el acceso a la vía pública desde el lugar donde habitualmente resida el animal.

6. Todo tenedor de un animal de compañía será responsable absoluto por cualquier mordedura, lesión o daño que el animal provoque a personas, a otros animales o a bienes de terceros.

7. Por último, se debe impedir que el animal implique una molestia o perjuicio para los vecinos, razón por la cual deberá:

a) Impedir ruidos molestos,

b) Recoger las heces con periodicidad,

c) Evitar los malos olores por medio del lavado y desinfección diaria de los lugares donde ellos se encuentren.

Estas normas prevén sanciones para el caso de por infracciones que afecten la protección y el bienestar animal, y las tipifica como: "toda acción u omisión contraria a las normas

\footnotetext{
Ver artículo 14 del Decreto 204/017
} 
de tenencia responsable o de bienestar animal previstas en la ley $\mathrm{N}^{\circ} 18.471$, modificativas y concordantes" ${ }^{6}$ y sus decretos reglamentarios.

Conforme a lo dispuesto por el artículo 29 del Decreto Reglamentario, dependiendo del tipo de norma vulnerada las infracciones se clasificarán en:

a. de bienestar animal

b. de tenencia responsable

c. administrativas

Para que proceda la aplicación de una sanción es necesario que previamente se formule una denuncia frente a la Comisión de Tenencia Responsable y Bienestar Animal (COTRyBA). Una vez que intervenga la Comisión, analice el caso y considere que existe una infracción, podrá proceder a la aplicación de una sanción. Valorando la gravedad de las conductas acaecidas, las infracciones cometidas y las normas violadas, las sanciones establecidas por la ley en su artículo 22 comienzan en el apercibimiento; luego se aplican multas económicas (de 1 a 500 unidades reajustables); confiscación de animales; cancelación o suspensión de autorizaciones, permisos o habilitaciones; hasta llegar a la prohibición temporal o definitiva de tenencia de animales.

\section{EL DERECHO DE PROPIEDAD}

\section{A) CONCEPTO Y LÍMITES}

El derecho de propiedad ha sido definido como "aquel derecho por medio del cual un sujeto puede ser propietario de bienes, y de ese derecho, a poder ser propietario, se deriva el de usar los bienes de que uno es propietario, de gozar del mismo y de disponer libremente de ellos" Asimismo Martín Risso Ferrand se refiere al derecho de propiedad diciendo que "el derecho reconocido de propiedad implica que cada habitante de la República, y por ese solo hecho, tiene el derecho subjetivo perfecto a ser propietario, o con mayor precisión a

\footnotetext{
Decreto 204/017. Artículo 28

Fernando López Quijano, "La propiedad y sus limitaciones en el derecho uruguayo": 3. http://www.lopezquijano.com/LA\%20PROPIEDAD\%20Y\%20SUS\%20LIMITACIONES\%20EN\%20EL\%20DERECHO\%20 URUGUAYO.pdf. Acceso el día 02 de febrero de 2018.
} 
poder ser propietario. Así el derecho reconocido aparece como una aptitud ilimitable de cada sujeto" 8

El derecho de propiedad ha sido consagrado tanto en nuestro sistema jurídico interno como a nivel internacional, con el Derecho Internacional de los Derechos Humanos ${ }^{9}$ Los instrumentos de Derecho Internacional más relevantes que reconocen y consagran el derecho de propiedad son la Declaración Universal de Derechos Humanos de fecha 10 de diciembre de 1948, que en su artículo 17 dispone: "1. Toda persona tiene derecho a la propiedad, individual y colectivamente. 2 . Nadie será privado arbitrariamente de su propiedad.”. Por otra parte, a nivel regional la Convención Americana de Derechos Humanos (también conocida como Pacto de San José de Costa Rica) establece en su artículo 21 "1. Toda persona tiene derecho al uso y goce de sus bienes. La ley puede subordinar tal uso y goce al interés social. 2. Ninguna persona puede ser privada de sus bienes, excepto mediante el pago de indemnización justa, por razones de utilidad pública o de interés social y en los casos y según las formas previstas por la ley..."

En el derecho material interno, el derecho de propiedad se encuentra reconocido como preexistente ${ }^{10}$ en el artículo 7 de la Constitución, que enuncia "Los habitantes de la República tienen derecho a ser protegidos en el goce de su vida, honor, libertad, seguridad, trabajo y propiedad. Nadie puede ser privado de estos derechos sino conforme a las leyes que se establecieren por razones de interés general”. Risso Ferrand sostiene que "de la lectura de esta disposición se advierte con relativa facilidad la existencia de dos tipos o categorías de derechos. Por un lado, el derecho a la vida, el derecho al honor, etc. Y por otra parte el derecho a ser protegido en el goce del honor, etc." ${ }^{11}$ Lo que afirma Risso Ferrand es que por una parte se reconoce el derecho preexistente a la vida, honor, libertad, seguridad, trabajo y propiedad, mientras que por otra parte se consagra y establece en el texto constitucional el derecho a ser protegido en el goce de los derechos mencionados en el inciso primero de la norma. La distinción entre derechos preexistentes y derechos consagrados del artículo 7 , indudablemente nos conduce a la interrogante de ¿cuáles son los derechos que pueden ser limitados con arreglo a las disposiciones de la Constitución? El mismo autor sostiene que

\footnotetext{
$8 \quad$ Martín Risso Ferrand, Derecho constitucional. Tomo I. (Montevideo: FCU. 2005), 437.

9 "Esta rama del Derecho, al principio dentro del Derecho Internacional Público, rápidamente fue perfilando sus propios matices y definiendo sus propias pautas y principios interpretativos, lo que condujo a la separación del Derecho Internacional Público transformándose en una rama autónoma” Martín Risso Ferrand, ¿Qué es la Constitución? (Montevideo: Universidad Católica del Uruguay. 2011), 58.

${ }_{10}$ De acuerdo con la concepción jusnaturalista de nuestra Carta, Justino Jiménez de Aréchaga sostuvo que no se pretende crear los derechos enunciados en el artículo 7, sino proclamar su existencia y garantías, concibiendo su existencia previa a la elaboración del texto constitucional. Justino Jimenez de Arechaga, "La Constitución Nacional' Edicion Camara de Senadores, tomo I, (Montevideo, 1992). 210.

${ }^{11}$ Martín Risso Ferrand. Derecho constitucional. Tomo I. (Montevideo, FCU. 2da. Edición. 2006.), 464.
} 
la interpretación de la doctrina mayoritaria con respecto a la segunda oración del artículo 7 refiere únicamente a los derechos consagrados, ya que, a su entender, los derechos preexistentes no pueden ser objeto de privación o limitación alguna ${ }^{12}$ debido a que los ordenamientos jurídicos no los crean, sino que los reconocen como anteriores a su vigencia. Luego, se presenta una nueva incógnita, acerca de cómo deben ser interpretadas las limitaciones en el goce de los derechos fundamentales. Interpretar significa desentrañar el verdadero sentido o significado de una norma. La Real Academia Española señala que este término, proveniente del latín interpretari, significa "determinar el significado y alcance de las normas jurídicas"13 La doctrina constitucionalista, y en mayor grado Risso Ferrand, señala que para interpretar el ordenamiento jurídico de forma correcta debe hacerse "desde la Constitución", teniendo en cuenta todas las disposiciones, valores y principios constitucionales. Para la interpretación de los derechos fundamentales es necesario que se encuentren delimitados en cuanto a su concepto y alcance, y en caso de diversas interpretaciones posibles deberá preferirse aquella que otorgue mayor amplitud o efectividad al derecho humano en juego. ${ }^{14}$ Teniendo en cuenta que ante varias interpretaciones posibles debe tomarse en cuenta aquella que permita mayor plenitud al derecho en juego, y utilizando un método de razonabilidad contradictorio, puede afirmarse que en caso de que existan limitaciones a un derecho fundamental deberán ser interpretadas de forma estricta o restrictiva, reducida a menores límites o a su mínima expresión. ${ }^{15}$

\section{B) LIMITACIÓN AL DERECHO DE PROPIEDAD POR DISPOSICIONES DEL REGLAMENTO DE COPROPIEDAD}

El reglamento de copropiedad ha sido definido como "el cuerpo normativo que regula las relaciones entre los copropietarios del edificio sometido al régimen de propiedad horizontal" 16 A partir de esta definición puede sostenerse que el reglamento de copropiedad es entendido como la ley que va a regir la vida en común en el condominio, y que tiene como destino establecer la distribución de los bienes, el ejercicio de los derechos y las obligaciones contraídas por los copropietarios. En efecto, la doctrina especialista en la materia ha señalado que en virtud de que el reglamento de copropiedad es el cuerpo normativo específico que regirá en cada edificio de propiedad horizontal, podrían establecerse en él todas aquellas

Risso Ferrand. Derecho constitucional ..., 477

dle.rae.es/?id=LwUON38 consultado el día 10 de febrero de 2018.

Risso Ferrand. Derecho constitucional..., 281-282

http://dle.rae.es/?id=WEmQSsB consultada el día 10 de febrero de 2018

Julio Ramos Olivera, Manual práctico de propiedad horizontal. 7 ma edición (Montevideo, FCU, 2012), 27 
cláusulas que se consideren adecuadas para la regulación de la vida en común. Sin embargo, es menester destacar que esta potestad no es absoluta, debido a que existen ciertas materias que el reglamento de copropiedad no puede modificar, tales como las normas de orden público, los derechos constitucionales y las normas específicas de propiedad horizontal.

Ante esto, surge la interrogante acerca de si por reglamento de copropiedad puede prohibirse la tenencia de mascotas o animales de compañía en los edificios de propiedad horizontal. Como se dijo anteriormente, conforme a las disposiciones legales y reglamentarias vigentes, las mascotas y animales de compañía son considerados objetos de propiedad privada, y por lo tanto están sometidos a la protección de normas especiales y de aquellas reguladoras del derecho de propiedad. Como consecuencia, y en virtud de lo dispuesto por el artículo 7 de la Constitución, tales derechos solamente pueden ser limitados por una ley dictada por razones de interés general. ${ }^{17}$

Por lo tanto, teniendo en cuenta que los derechos fundamentales solamente pueden ser limitados por una ley dictada por razones de interés general, y considerando que el reglamento de copropiedad no tiene rango legal ni cumple con el procedimiento utilizado para la creación de la ley (no es dictado por el órgano competente ni cumple ningún proceso constitucional), puede concluirse que la tenencia de mascotas o animales de compañía en edificios de propiedad horizontal no puede ser prohibida por reglamento de copropiedad. Si así se hiciera podría reclamarse su inconstitucionalidad en la vía judicial, y tampoco podrán aplicarse multas y/o sanciones a aquellos tenedores de animales que ejerzan la tenencia de manera responsable.

Sería de relevancia la mención de antecedentes jurisprudenciales en este punto, pero no se incluyen por ser inexistentes a la fecha.

\section{C) TENENCIA IRRESPONSABLE DE ANIMALES QUE CAUSE PERJUICIOS A COPROPIETARIOS}

Ante el ejercicio irresponsable de la tenencia de mascotas o animales de compañía cualquier persona puede formular una denuncia ante la COTRyBA, en un formulario como el que se muestra más adelante, para que la institución asuma su función como organismo de contralor del bienestar animal y analice el caso concreto, para luego determinar si existe infracción a alguna norma, y eventualmente aplicar sanciones.

\footnotetext{
17 A esto se le llama principio de reserva legal. Solamente la ley en sentido orgánico-formal (dictada por el órgano competente y cumpliendo con los procedimientos constitucionales) es apta para la limitación o privación en el goce de los derechos fundamentales. Sostiene Risso Ferrand que aparece como una garantía básica de los derechos humanos.
} 
Además, por tratarse de edificios de apartamentos, en los cuales las personas tienen vecinos con los que comparten espacios comunes, puede ocurrir que las mascotas o animales causen perjuicios a terceros, ocasionando molestias o incluso dańos físicos y/o materiales. Ante esto, independientemente de las reclamaciones civiles y/o penales que pueda efectuar la víctima por los daños sufridos, en atención a lo dispuesto por el artículo 10 de la Ley 10.751 de Propiedad Horizontal ${ }^{18}$, se podrá denunciar la situación frente a la asamblea y solicitar la aplicación de una multa, ya sea que se encuentre prevista en la ley o en el Reglamento de Copropiedad.

\section{CONCLUSIONES}

Partiendo de la hipótesis enunciada, según la cual en gran parte de los edificios de propiedad horizontal se prohíbe la tenencia de mascotas o animales de compañía en virtud de la inexistencia de normativa al respecto se ha llegado a la conclusión de que existe en nuestro derecho positivo normativa vigente respecto a la tenencia y cuidado de los animales, que se encarga de regular las conductas humanas para con los animales y respecto de terceras personas, estableciendo un régimen de responsabilidad social y la posibilidad de imponer sanciones si se incumplieren las normas.

Asimismo, se analizó la legitimidad de las cláusulas de los reglamentos de copropiedad que prohíben la tenencia de animales en edificios de propiedad horizontal, frente a las cuales se encuentran dos posturas: por un lado la del Dr. Julio Ramos Olivera (previa al decreto 204/017), quien se manifestó a favor de la inclusión de la cláusula y apoya su legitimidad en virtud de la inexistencia de normativa al respecto ${ }^{19}$, y la otra postura, sostenida por la Sra. Ana Rita Colombo, integrante de la COTRyBA, quien se manifiesta en contra de dichas cláusulas, en virtud de que considera que son violatorias del derecho de propiedad, regulado constitucionalmente. La Dra. Bettina Molina se ha pronunciado en la misma línea de la Sra. Colombo, manifestando que debido a que los animales son considerados objetos de propiedad, su prohibición por reglamento de copropiedad violaría las disposiciones constitucio-

\footnotetext{
18 Artículo 10: "El Juez, a petición del administrador o de cualquier propietario, podrá aplicar a quien infrinja lo dispuesto en el artículo anterior multa que fijará entre $0.5 \%$ (cero cinco por ciento) y el $20 \%$ (veinte por ciento) del valor del departamento determinado por la Dirección General del Catastro Nacional o quien haga sus veces..."

19 No se ha encontrado opinión del autor que sea posterior al Decreto 204/017.
} 
nales. ${ }^{20}$ Luego, el Dr. Alejandro Rey Jiménez de Aréchaga, en entrevista radial sostuvo que "puede sostenerse que los reglamentos no tienen validez alguna para establecer la prohibición de la tenencia de mascotas en un edificio, ya que se estaría limitando el derecho de propiedad de los propietarios y/o inquilinos sobre sus mascotas, y esto solo puede hacerse por ley." ${ }^{21}$

En definitiva, si bien no se desconoce la posibilidad de regular la convivencia respecto de las mascotas mediante el Reglamento de Copropiedad, la prohibición de tenencia de mascotas y animales de compañía debería considerarse inconstitucional, y por lo tanto, si un copropietario alegase un interés directo, personas y legítimo, podría impugnar la cláusula prohibitiva ante la justicia competente.

Para citar este artículo: Fascioli, Agustín, "La tenencia de mascotas en edificios de propiedad horizontal y su prohibición por reglamento de copropiedad", https://doi.org/10.22235/rd.v0i17.1575 Revista de Derecho, $\mathrm{N}^{\circ} 17$ (jul. 2018), ISSN 1510-3714, ISSN On line 2393-6193: 153-164.

\section{BIBLIOGRAFÍA}

Blengio Valdés, Mariana. Código de Derechos Humanos. Montevideo: Fundación Konrad Adenauer, 2010.

Diccionario de la Real Academia Española, http://dle.rae.es

Estudio Posadas, Posadas y Vecino, "Tenencia de mascotas en edificios y los derechos en juego", en Columna de Posadas, Posadas \& Vecino en radio El Espectador: 12 de junio de 2017. http://www.ppv.com.uy/noticias/ampliada/357

Justino Jimenez de Arechaga. “La Constitución Nacional'. Montevideo, 1992.

López Quijano, Fernando. Lapropiedadysus limitaciones en el derecho uruguayo. http://www.lopez-quijano.com/LA\%20PROPIEDAD\%20Y\%20SUS\%20LIMITACIONES\%20 EN\%20EL\%20DERECHO\%20URUGUAYO.pdf.

Meléndez, Florentín. Instrumentos internacionales sobre derechos humanos aplicables a la administración de justicia. Fundación Konrad Adenauer. Bogotá, 2012.

\footnotetext{
20 http://www.diariovecinos.com.uy/2017/03/04/es-legal-prohibir-la-tenencia-de-animales-en-edificios-ocomplejos-de-viviendas/ Consultada el día 13 de febrero de 2018.

${ }_{21}$ http://www.ppv.com.uy/noticias/ampliada/357 consultada el día 15 de febrero de 2018.
} 
Molina, Betina: “¿Eslegal prohibirlatenenciadeanimalesenedificiosocomplejosdeviviendas?”, http://www.diariovecinos.com.uy/2017/03/04/es-legal-prohibir-la-tenencia-deanimales-en-edificios-o-complejos-de-viviendas/

Organización mundial de sanidad animal, "El bienestar animal de un vistazo", http://www. oie.int/es/bienestar-animal/el-bienestar-animal-de-un-vistazo/

"Polémica por la tenencia de mascotas en los edificios", https://www.elpais.com.uy/informacion/polemica-tenencia-mascotas-edificios.html

Ramos Olivera, Julio. Manual práctico de propiedad horizontal. Fundación de Cultura Universitaria. Montevideo, 2012.

Risso Ferrand, Martín. ¿Qué es la Constitución? Universidad Católica del Uruguay. Montevideo, 2011.

Risso Ferrand, Martín. Derecho Constitucional. Tomo I. Fundación de Cultura Universitaria. Montevideo, 2005.

Risso Ferrand, Martín. Derecho Constitucional. Tomo I. Fundación de Cultura Universitaria Montevideo, 2006. 